\title{
Eating Habits of College Students in Relation to Obesity
}

\author{
$\$$ \\ K.L.L. Pineda, RND, MSPH a*, \\ C. Gonzalez-Suarez, $M D, P h D^{\text {b }}$, \\ R.V. Espino, CSCS, MSHMS c, \\ C.J. Escuadra, MHPE d, \\ S.A. Balid-Attwell, MA ${ }^{\circ}, K$. Devora, MSc ${ }^{f}$, \\ D. Mendoza, MSc, RND 9
}

\section{ABSTRACT}

Objective: This paper aims to determine the causal relationship of eating habits, smoking, alcohol drinking and sleeping in overweight and obese college students.

Participants: There were 850 female students with age range from 15 to 39 and 551 male students with age range from 15 to 25 years old.

Methods: A cross-sectional study using a questionnaire on eating habits was adapted from a previously published study by Ruka Sakamaki, 2005. The height and weight were calculated for body mass index. Waist circumference was also measured. Simple logistic regression and multiple regression were utilized to analyze the collected data.

Results: There were significantly more males who were overweight and obese when compared with females. Multivariate analysis showed that eating breakfast and vegetables and not having frequent snacks are protective factors for being overweight and obese in both genders.

Conclusion: The study presented the importance of having breakfast, eating vegetables and taking less snacks for the prevention of excess weight and obesity among college students.

Keywords: eating habit, obesity, overweight, college students

\section{INTRODUCTION}

An increase in overweight and obese students has been a significant and legitimate public health issue observed in both developed and developing nations worldwide with prevalence among Asian countries ranging from $12.2 \%$ to $35.1 \%$.[1] In the Philippines,
Karen Leslie L. Pineda, RND, MSPH

klpineda@ust.edu.ph; kleepineda@yahoo.com

a Department of Sports Science, College of Rehabilitation Sciences, University of Santo Tomas

b Department of Sports Science, College of Rehabilitation Sciences and Faculty of Medicine and Surgery,

University of Santo Tomas

c Department of Sports Science, College of Rehabilitation Sciences, University of Santo Tomas d Department of Physical Therapy, College of Rehabilitation Sciences, University of Santo Tomas

e Department of Occupational Therapy, College of Rehabilitation Sciences, University of Santo Tomas

f Department of Physical Therapy, College of Rehabilitation Sciences, University of Santo Tomas

$g$ Department of Nutrition and Dietetics, College of Education, University of Santo Tomas 
the $8^{\text {th }}$ National Nutrition Survey (2013) [2] reported an increased trend on overweight and obesity prevalence from 1993 to 2013 by $3.23 \%$ and $14.5 \%$ among adolescents (aged 10-19 years old) and young adults (aged 20 years old and above), respectively. The survey revealed as well that three in every ten adults are overweight and obese, particularly females $(34.4 \%)$ than males $(27.6 \%)$. This is alarming as overweight and obesity persists in adulthood and may contribute to a number of health concerns including heart disease, hypertension, diabetes and cancer.[3]

The causes of overweight and obesity among adults encompass genetic and environmental factors [4] and unhealthy lifestyles such as lack of physical activity, overeating and short sleep duration.[5-8] These unhealthy behavior patterns were found to be common among entry level college students. [9] The transitional semester from high school to college is also marked by increased risk-taking behaviors including alcohol consumption and smoking. $[2,10,11]$ Though there is already an increased interest on association of these unhealthy habits with overweight and obesity among college students, [5-8] the direction and strength of their correlation is still inconclusive. For example, non-consumption of breakfast, though found to be a risk factor among dental college students (OR 2.39, 95\%) [12], was found not to have a significant association among university students in Canada [13] and Malaysia. [14] Though the explanation for these differences is yet to be further explored, most studies attribute inconsistent findings to environmental and cultural differences. [13]

The development and implementation of effective health promotion interventions focusing on healthy lifestyles are imperative in the school setting considering that college life is the period of behavioral and lifestyle explorations that could have a lasting effect on health behaviors in adulthood. Currently, there are local researches that have explored eating practices and weight status among Filipinos across all ages. $[7,15,16]$ However, to the authors' knowledge, there appears to be limited published local investigations on eating habits and lifestyle and their association with overweight and obesity among college students. Therefore, this study aims to describe the lifestyle habits which include eating, smoking, alcohol drinking and sleeping of emerging adults in Manila and determine if there is a causal relationship in being overweight and obese.

\section{METHODOLOGY}

\section{Ethical Consideration}

The study has been granted ethics approval by the University of Santo Tomas College of Rehabilitation Sciences (Protocol Number: Fl-2014-006).

\section{Study Design}

This cross sectional study was carried out among first to fourth year college students of the University of Santo Tomas.

\section{Participants and Sample Size}

This study was conducted at the University of Santo Tomas (UST) campus which is located in the City of Manila, Philippines. The university houses 23 colleges with a total population of 42,000 students coming from different income groups. Participants were first to fourth year college students enrolled during the academic school year 2015-2016. They were selected using the random cluster sampling methodology. Based on the university's student database, the Santo Tomas E-Service providers (STEPS) provided the list of sections. The sample size was calculated using OpenEpi (2016). From the University's total population of 42,000 college students and a national prevalence of $23.3 \%$ for being overweight and obese from ages 18 to 39 years respectively, a sample of 1430 were recruited to achieve $90 \%$ power. There were no exclusion criteria for this study.

\section{Study Protocol}

An orientation meeting was held for all members of the research team prior to data gathering to ensure the smooth flow and accuracy of collection processes. The assistant head of the research team discussed proper protocols and facilitated the hands-on training of the research team members relative to equipment use as well as weight and height determinations. Testing schedules were arranged with the respective college secretaries and approval of the concerned deans. On the day of data gathering, participants were asked to answer the consent forms and the socio-demographic data sheet. Thereafter, anthropometric measurements were taken and food habit questionnaires distributed to the participants. Data gathering was held in different buildings of 
the scheduled colleges for the day. A reserved room was provided to the research team for purposes of data gathering.

\section{Outcome Measures}

Anthropometric Measurements

Body Mass Index (BMI). This is a measure of weight in relation to a person's height. In order to classify the participants into having normal weight, being overweight and obese, the International Obesity Task Force's gender- and age-specific cut-off points were used.[17] Weight was measured to the nearest 0.1 kilogram while height was measured to the nearest $0.1 \mathrm{~cm}$ using the weighing scale and Detecto stadiometer, respectively. Participants were asked to remove their shoes and socks and empty their pockets while standing in a relaxed position.

Waist Circumference (WC). This circumference dimension is used to determine body fat distribution and the presence of abdominal or central obesity. Using the Lafayette tape measure, the student's waist was measured in centimeters $(\mathrm{cm})$.

Food Habit Questionnaire. The food habit questionnaire was adapted from a published study undertaken by Ruka Sakamaki (2005) where food practices of Japanese and Korean female students were compared. The original questionnaire was based on results of a national dietary survey that was conducted by the Health and Labor Ministry of Japan. [18] This same food habit questionnaire was further standardized relative to its usefulness among university students in various investigations.[18-20] To comprehensively assess the habits of participants six items were added to the 11 -item original questionnaire resulting in a modified 17-item questionnaire consisting of fourteen (14) questions pertaining to eating habits and three (3) questions on lifestyle practices focusing on sleeping, drinking alcohol and smoking.

\section{Treatment of Data}

Each item was answered by students using the Likert range from 1 to 6 . To obtain a collective score for the eating, drinking, smoking and sleeping habits among participants, researchers recorded and treated the responses following the scoring method for the RAND 36-Item Health Survey.[21] Numerical values ranging from 1-6 were allocated per item depending on the number of options per item. Highest value was given to good practices (eg, regular meal intake, frequent consumption of vegetables and fruits, non-smoking and non-drinking of alcoholic beverage, sleeping for at least 6 hours) while lower values were given to bad practices. For equal weight distribution in all items, a maximum score of 1 (obtained by dividing the numerical value to the total number of options per item) was assigned to each question. A score of 10 and above, based on possible responses of participants for all eating questions, was considered as good eating practice while a score of 1 for drinking, sleeping and smoking was considered as a good habit.

\section{Statistical Analysis}

Using STATA 13, mean, standard deviation (SD), frequency and proportions were used to describe the demographics of included participants. Percentages were utilized to report the prevalence of overweight and obesity. Chi square and t-test were used to compare the bad habits according to gender and BMI. Simple logistic regression was used to determine the relationship of obesity to eating, smoking and sleeping habits. All factors in the logistic regression with a $p$-value of $\leq 0.05$ were included in the model. Multiple regression was then utilized to determine factors that are significantly associated with being overweight and obese. A p-value of less than or equal to 0.05 was considered significant.

\section{RESULTS}

A total of 1401 subjects composed of 850 (60.7\%) female and 551 (39.3\%) male students participated in this study with ages ranging from 15 to 39 years old and 15 to 25 years old for females and males, respectively. Waist circumference showed significant differences between genders where males had a larger measure. There were significantly more males who were overweight and obese with $26.86 \%$ and $12.16 \%$ as compared to the females with $18.35 \%$ and $7.53 \%$ as being overweight and obese (Table 1).

About $75 \%$ of students were found to have bad eating habits and $90 \%$ had bad sleeping habits. Both male and female students almost had the same per- 
Table 1. Comparison of anthropometric measurements by sex

\begin{tabular}{lccc}
\hline & Male $(\mathbf{n}=551)$ & Female $(\mathbf{n}=850)$ & p-value \\
\hline Age (mean \pm SD) & $18.32 \pm 1.68$ & $18.30 \pm 1.70$ & $<0.01^{*}$ \\
BMI (mean \pm SD) & $24.21 \pm 4.64$ & $22.97 \pm 4.97$ & $<0.01^{*}$ \\
Classification (n, \%) & & & $<0.01^{*}$ \\
- Underweight & $53(9.62)$ & $108(12.71)$ & $522(61.41)$ \\
- Normal & $283(51.36)$ & $156(18.35)$ & $64(7.53)$ \\
- Overweight & $148(26.86)$ & $76.64 \pm 15.12$ & $<0.01^{*}$ \\
- Obese & $67(12.16)$ &
\end{tabular}

Age: years old; BMl: kg/m²; Waist Circumference: centimeters

Table 2. Comparison of bad habits by gender

\begin{tabular}{|c|c|c|c|c|c|c|c|}
\hline \multirow{2}{*}{$\begin{array}{l}\text { Student with: } \\
(\mathbf{n}, \%)\end{array}$} & \multicolumn{2}{|c|}{ Total $(n=1401)$} & \multicolumn{2}{|c|}{ Male $(n=551)$} & \multicolumn{2}{|c|}{ Female $(n=850)$} & \multirow{2}{*}{ p-value } \\
\hline & $\mathrm{N}$ & $\%$ & $\mathbf{n}$ & $\%$ & $\mathbf{n}$ & $\%$ & \\
\hline Bad eating habits & 1036 & 73.95 & 422 & 76.59 & 614 & 72.24 & NS \\
\hline $\begin{array}{l}\text { Alcohol drinking } \\
\text { habits }\end{array}$ & 84 & $(6.00)$ & 57 & 10.34 & 27 & 3.18 & $<0.01 *$ \\
\hline Smoking habits & 116 & $(8.28)$ & 58 & 10.53 & 58 & 6.82 & 0.01 * \\
\hline Bad sleeping habits & 1261 & $(90.01)$ & 513 & 93.10 & 748 & 88.00 & $<0.01 *$ \\
\hline
\end{tabular}

NS: not significant

centage of having bad eating habits. Significant differences between the genders were seen as the male participants showed higher prevalence of bad sleeping habits, smoking and alcohol drinking (Table 2).

There is a high percentage of bad eating and sleeping habits, alcohol drinking and smoking among students with normal BMI followed by those in the combined category of overweight and obese students in both genders. However, no significant differences ( $p$-values: $>0.05$ ) were observed from the results as seen in Table 3.

Univariate analysis as reflected on Table 4 showed that for both males and females, eating breakfast, taking frequent snacks, eating vegetables, drinking alcohol and smoking habits were found to be significantly associated with being overweight and obese, with $p$-value equal to $0.04,<0.01,<0.02,0.02$ and 0.01 , respectively. Specifically, eating breakfast with an odds ratio (OR) of 0.65 (0.43-0.98), eating frequent snacks with an OR of $0.33195 \%$ Confidence Interval $[\mathrm{Cl}]: 0.21,0.52)$, and eating vegetables with an OR of $0.79(95 \% \mathrm{Cl}: 0.10,91)$ were found to be protective factors of being overweight and obese. While drinking alcohol with an OR of $1.34(95 \% \mathrm{Cl}: 1.05,1.72)$ and smoking habits with an $\mathrm{OR}$ of $1.41(95 \% \mathrm{Cl}: 1.10,1.81)$ were found to be risk factors of being overweight and obese.

For males, eating breakfast and taking frequent snacks were significantly associated with being overweight and obese with a p-value equal to $<0.01$ and 0.01 , respectively. Specifically, these two dietary factors were found to be protective of being overweight and obese with an OR of $0.30195 \% \mathrm{Cl}$ : $0.15,0.59)$ for eating breakfast and $0.46(95 \% \mathrm{Cl}$ : $0.23,0.85)$ for eating frequent snacks.

For females, taking frequent snacks, eating vegetables, eating fruits, eating home-cooked breakfast, eating fast food, drinking alcohol and smoking were found to be significantly associated with being overweight and obese with a p-value equal to $<0.01$, $0.01,0.02,0.01,0.01,0.03$ and 0.01 , respectively. Specifically, eating frequent snacks with an OR of 0.28 (95\% Cl: $0.15,0.52)$, vegetables with an $\mathrm{OR}$ of $0.48(95 \% \mathrm{Cl}: 0.29,0.76)$, eating fruits with an OR of $0.25(95 \% \mathrm{Cl}: 0.16,0.76)$ and eating fast food with an OR of $0.68(95 \% \mathrm{Cl}: 0.50$, 0.92) were found to be protective factors of being overweight and obese. While eating home-cooked breakfast with an OR of 3.09 (95\% Cl: 1.51-6.32), drinking alcohol with an OR of $1.25195 \% \mathrm{Cl}$ : 
Table 3. Comparison of bad habits by BMl category and sex

\begin{tabular}{|c|c|c|c|c|}
\hline$(n, \%)$ & Underweight & Normal & Overweight & Obese \\
\hline \multicolumn{5}{|c|}{ Male and Female Students with $(n=1401)$} \\
\hline Bad eating habits $(n=1036)$ & $114(11.00)$ & $599(57.82)$ & $220(21.24)$ & $103(9.94)$ \\
\hline Alcohol drinking habits $(n=84)$ & $5(5.95)$ & $48(57.14)$ & $24(28.57)$ & $7(8.33)$ \\
\hline Smoking habits $(n=116)$ & $6(5.17)$ & $68(58.62)$ & $31(26.72)$ & $11(9.48)$ \\
\hline Bad sleeping habits $(n=1260)$ & $146(11.66)$ & $721(57.18)$ & $274(21.73)$ & $119(9.44)$ \\
\hline \multicolumn{5}{|l|}{ Male Students with $(n=551)$} \\
\hline Bad eating habits ( $n=422$ ) & $38(9.00)$ & $213(50.47)$ & $116(27.49)$ & $55(13.03)$ \\
\hline Alcoholic drinker $(n=57)$ & $2(3.51)$ & $29(50.88)$ & $19(33.33)$ & $7(12.28)$ \\
\hline Smoker $(n=58)$ & $3(5.17)$ & $30(51.72)$ & $18(31.03)$ & $7(12.07)$ \\
\hline With bad sleeping habits $(n=513)$ & $53(9.75)$ & $267(52.05)$ & $133(25.93)$ & $60(12.27)$ \\
\hline \multicolumn{5}{|l|}{ Female Students with $(n=850)$} \\
\hline Bad eating habits $(n=614)$ & $76(12.38)$ & $386(62.87)$ & $104(16.94)$ & $48(7.82)$ \\
\hline Alcohol drinking habits $(n=27)$ & $3(11.11)$ & 19 (70.37) & $5(18.52)$ & - \\
\hline Smoking habits $(n=58)$ & $3(5.17)$ & $38(65.52)$ & $13(22.41)$ & $4(6.90)$ \\
\hline Bad sleeping habits ( $n=759$ ) & 108 (12.09) & 454 (60.70) & $141(18.85)$ & $56(7.49)$ \\
\hline
\end{tabular}

$\%$ : row percentage

p-values computed using ANOVA: $>0.05$

Table 4. Univariate analysis of factors associated with overweight and obesity

\begin{tabular}{|c|c|c|c|c|c|c|c|}
\hline & & \multicolumn{2}{|c|}{ MALES AND FEMALES } & \multicolumn{2}{|c|}{ MALES } & \multicolumn{2}{|c|}{ FEMALES } \\
\hline & & $\begin{array}{c}\text { OR } \\
95 \% \mathrm{Cl}\end{array}$ & p-value & $\begin{array}{c}\text { OR } \\
95 \% \mathrm{Cl}\end{array}$ & p-value & $\begin{array}{c}\text { OR| } \\
95 \% \mathrm{Cl}\end{array}$ & p-value \\
\hline \multirow{12}{*}{$\begin{array}{l}\text { GOOD } \\
\text { EATING } \\
\text { HABITS }\end{array}$} & Regular meal & $\begin{array}{c}1.04 \\
(0.67-1.64)\end{array}$ & NS & $\begin{array}{c}0.88 \\
(0.44-1.76)\end{array}$ & NS & $\begin{array}{c}1.08 \\
(0.59-1.99)\end{array}$ & NS \\
\hline & Eating breakfast & $\begin{array}{c}0.65 \\
(0.43-0.98)\end{array}$ & $0.04^{*}$ & $\begin{array}{c}0.30 \\
(0.15-0.59)\end{array}$ & $<0.01$ * & $\begin{array}{c}0.86 \\
(0.50-1.47)\end{array}$ & NS \\
\hline & $\begin{array}{l}\text { Taking number of } \\
\text { meals/day }\end{array}$ & $\begin{array}{c}0.68 \\
(0.32-1.41)\end{array}$ & NS & $\begin{array}{c}0.60 \\
(0.20-1.78)\end{array}$ & NS & $\begin{array}{c}0.46 \\
(0.16-1.29)\end{array}$ & NS \\
\hline & $\begin{array}{l}\text { Taking frequent } \\
\text { snacks/week }\end{array}$ & $\begin{array}{c}0.33 \\
(0.21-0.52)\end{array}$ & $<0.01$ * & $\begin{array}{c}0.46 \\
(0.23-0.85)\end{array}$ & 0.01 * & $\begin{array}{c}0.28 \\
(0.15-0.52)\end{array}$ & $<0.01^{*}$ \\
\hline & Eat vegetables & $\begin{array}{c}0.79 \\
(0.10-.91)\end{array}$ & $<0.02^{*}$ & $\begin{array}{c}0.39 \\
(0.29-1.60)\end{array}$ & NS & $\begin{array}{c}0.48 \\
(0.29-0.76)\end{array}$ & 0.01 * \\
\hline & Eat fruits & $\begin{array}{c}0.53 \\
(0.49-2.49)\end{array}$ & NS & $\begin{array}{c}0.14 \\
(0.13-2.43)\end{array}$ & NS & $\begin{array}{c}0.25 \\
(0.16-0.76)\end{array}$ & $0.02 *$ \\
\hline & $\begin{array}{l}\text { Eat with friends and } \\
\text { family }\end{array}$ & $\begin{array}{c}0.91 \\
(0.54-1.51)\end{array}$ & NS & $\begin{array}{c}1.11 \\
(0.55-2.27)\end{array}$ & NS & $\begin{array}{c}0.98 \\
(0.48-2.08)\end{array}$ & NS \\
\hline & $\begin{array}{l}\text { Eat a variety of } \\
\text { foods }\end{array}$ & $\begin{array}{c}0.85 \\
(0.35-2.04)\end{array}$ & NS & $\begin{array}{c}1.30 \\
(0.38-4.37)\end{array}$ & NS & $\begin{array}{c}0.61 \\
(0.17-2.15)\end{array}$ & NS \\
\hline & \multicolumn{7}{|c|}{ Eat home cooked meal for } \\
\hline & Breakfast & $\begin{array}{c}0.90 \\
(0.66-1.22)\end{array}$ & NS & $\begin{array}{c}0.47 \\
(0.20-1.09)\end{array}$ & NS & $\begin{array}{l}3.09 \\
(1.51-6.32)\end{array}$ & $<0.01^{*}$ \\
\hline & Lunch & $\begin{array}{c}0.82 \\
(0.46-1.47)\end{array}$ & NS & $\begin{array}{c}1.09 \\
(0.42-2.81)\end{array}$ & NS & $\begin{array}{c}0.88 \\
(0.41-1.91)\end{array}$ & NS \\
\hline & Dinner & $\begin{array}{c}0.62 \\
(0.35-1.10)\end{array}$ & NS & $\begin{array}{c}0.45 \\
(0.18-1.12)\end{array}$ & NS & $\begin{array}{c}0.79 \\
(0.37-1.69)\end{array}$ & NS \\
\hline
\end{tabular}


Table 4. Univariate analysis of factors associated with overweight and obesity (Continued)

\begin{tabular}{|c|c|c|c|c|c|c|c|}
\hline & & \multicolumn{2}{|c|}{ MALES AND FEMALES } & \multicolumn{2}{|c|}{ MALES } & \multicolumn{2}{|c|}{ FEMALES } \\
\hline & & $\begin{array}{c}\text { OR } \\
95 \% \mathrm{Cl}\end{array}$ & p-value & $\begin{array}{c}\text { OR } \\
95 \% \mathrm{Cl}\end{array}$ & p-value & $\begin{array}{c}\text { OR| } \\
95 \% \mathrm{Cl}\end{array}$ & p-value \\
\hline \multirow{3}{*}{$\begin{array}{l}\text { BAD } \\
\text { EATING } \\
\text { HABITS }\end{array}$} & Eat fried foods & $\begin{array}{c}1.12 \\
(0.87-1.45)\end{array}$ & NS & $\begin{array}{c}0.86 \\
10.57-1.30\end{array}$ & NS & $\begin{array}{c}1.41 \\
(1.01-1.98)\end{array}$ & NS \\
\hline & Skip meals & $\begin{array}{c}1.15 \\
(0.76-1.75)\end{array}$ & NS & $\begin{array}{c}1.42 \\
0.81-2.49\end{array}$ & NS & $\begin{array}{c}1.09 \\
(0.57-2.08)\end{array}$ & NS \\
\hline & Eat fast foods & $\begin{array}{c}0.91 \\
(0.73-1.14)\end{array}$ & NS & $\begin{array}{c}1.32 \\
10.94-1.87\end{array}$ & NS & $\begin{array}{c}0.68 \\
0.50-0.921\end{array}$ & $0.01 *$ \\
\hline \multicolumn{2}{|c|}{ Alcohol drinking habits } & $\begin{array}{c}1.34 \\
(1.05-1.72)\end{array}$ & $0.02 *$ & $\begin{array}{c}1.30 \\
(0.91-1.85)\end{array}$ & NS & $\begin{array}{c}1.25 \\
(1.01-1.52)\end{array}$ & $0.03 *$ \\
\hline \multicolumn{2}{|c|}{ Smoking habits } & $\begin{array}{c}1.41 \\
(1.10-1.81)\end{array}$ & $0.01 *$ & $\begin{array}{c}1.22 \\
(0.96-1.56)\end{array}$ & NS & $\begin{array}{c}1.28 \\
(1.08-1.52)\end{array}$ & $0.01 *$ \\
\hline \multicolumn{2}{|c|}{ Bad sleeping habits } & $\begin{array}{c}1.17 \\
(0.87-1.56)\end{array}$ & NS & $\begin{array}{c}1.08 \\
(0.09-1.28)\end{array}$ & NS & $\begin{array}{c}1.07 \\
(0.92-1.25)\end{array}$ & NS \\
\hline
\end{tabular}

* NS: not significant

Table 5. Multivariate analysis of factors associated with overweight and obesity

\begin{tabular}{lcccc}
\hline & Coefficient & OR & $\mathbf{9 5 \%} \mathbf{C l}$ & P-value \\
\hline All & & & & \\
Eat breakfast & -0.53 & 0.59 & $0.39-0.89$ & $0.01^{*}$ \\
Eat vegetables & -1.13 & 0.32 & $0.21-0.50$ & $<0.01^{*}$ \\
Taking frequent snacks/week & 0.72 & 2.05 & $1.25-3.36$ & $0.01^{*}$ \\
Male & & & & \\
Eat breakfast & -1.15 & 0.32 & $0.16-0.63$ & $<0.01^{*}$ \\
Taking frequent snacks/week & -0.73 & 0.48 & $0.25-0.92$ & $\mathrm{NS}$ \\
Female & & & & \\
Taking frequent snacks/week & 0.88 & 2.41 & $1.25-4.66$ & $0.01^{*}$ \\
Eat vegetables & -1.25 & 0.29 & $0.16-0.53$ & $<0.01^{*}$ \\
\hline
\end{tabular}

* NS: not significant

$1.01,1.52)$ and smoking with an OR of $1.28(95 \%$ $\mathrm{Cl}: 1.08,1.52)$ were found to be risk factors of being overweight and obese.

Multivariate analysis showed that eating breakfast and vegetables are protective in being overweight and obese for both genders with an OR of 0.59 (95\% Cl: $0.39,0.89)$ and $0.32(95 \% \mathrm{Cl}: 0.21$, $0.50)$, respectively, while taking frequent snacks is a risk factor in being overweight and obese (OR 2.05 $95 \% \mathrm{Cl}: 1.25,3.36)$. For males, eating breakfast and taking frequent snacks are protective from being overweight and obese with an OR of $0.32195 \%$ Cl: $0.16,0.63)$ and 0.48 (95\% Cl: $0.25,0.93)$. While for females, taking frequent snacks is a risk factor for being overweight and obese with an OR of $2.41(95 \% \mathrm{Cl}: 1.25,4.66)$ and eating vegetables is protective from being overweight and obese with an OR of $0.29(95 \% \mathrm{Cl}: 0.16,0.53)$ (Table 5).

\section{DISCUSSION}

The present data established that $58 \%$ of participants have normal $\mathrm{BMI}$ and a higher number was found among females (61.41\%). Thirty-one percent (31\%) are overweight and obese and higher prevalence was found among male students (39.02\%). It is assumed that female students are conscious about their weight status than males due to females' wanting to have a slim figure for attractiveness that leads to a lower rate of obesity among female students.[22] 
Similar findings were found across different studies done in Lebanon and Thailand where a majority of the students had normal BMI with a high prevalence among females while more male students were seen being overweight and obese. $[19,22]$ On the contrary, studies among university students in Turkey and China showed a high prevalence of students with normal BMI and lower prevalence of being overweight and obese. $[15,18]$

Based on the regression model, only breakfast, vegetables and snacking were found to have significant effects on overweight and obesity. The following paragraphs discuss in detail the various evidences that support these findings.

\section{Breakfast}

Using the multivariate analysis, this present study showed that across gender, eating breakfast is a protective factor in becoming overweight and obese. Similar results were observed in investigations undertaken among children and adolescents from many countries such as Fiji, [23] Japan, [18] and India.[5] Thompson-McCormick, et al. (2010) however, hypothesized that it is possible that eating pathology in general and not skipping breakfast promotes weight gain. They explained that skipping breakfast is being used as an intentional weight loss strategy by individuals who were categorized in the overweight classes.[23] In addition, Saikia, et al. (2016) revealed that overweight and obese adolescents consumed less number of major meals, skipped breakfast and had three or more extra snacks in between meals. It is likely that skipping meals may lead to eating more snacks and junk food every time they felt hungry. [24] On the contrary, students' BMI did not correlate with frequency of taking breakfast for both males and females among students in the Belgrade University in Serbia. In this study, taking breakfast is important because the university has an $8 \mathrm{am}$ to $6 \mathrm{pm}$ class schedule and no established lunch breaks in between classes.[25]

Breakfast is one of the most important daily meals. Eating breakfast may help with a nutrient-dense diet that can boost the ability to engage in regular physical activity.[25] Nutritionists recommend that one-third of daily calories should be eaten for breakfast. Skipping or missing breakfast will compromise health, energy levels, and cognitive performance leading to greater levels of hunger later in the day, producing greater overall intake. It is surprising that eating home-cooked breakfast was associated with overweight and obesity in females in this present study. However, this may be associated with the types of food present in a typical Filipino breakfast such as fried rice, egg and meat which could be dense and higher in caloric content.[7]

\section{Vegetables}

In this present study, eating vegetables was found to be a protective factor for being overweight and obese in both genders. Similar results were obtained in investigations undertaken by Al-Hazzaa, et al. (2012) among students in different universities situated in three cities of the Kingdom of Saudi Arabia. [26] Results showed a significant association between reduced vegetable intake and increased odds of having abdominal obesity among the students. Researches stated that the mechanism of vegetable intake and obesity prevention is not fully clear. However, it could be due to the total effect obtained from having healthy habits.

Inadequate intake of fruits and vegetables may have a negative impact on health. It is well published that vegetables and fruits contain low fat and energy density $(\mathrm{kcal} / \mathrm{g})$, but high in water and dietary fiber, which may increase satiety and decrease the hunger feeling after a meal. Therefore, including them in the diet can reduce a person's caloric intake, and thus, aid in managing weight. It has been reported that students from countries like Lebanon, China and Korea had regular intake of vegetables. $[18,19]$ In the Philippines, a study on vegetable consumption among selected public schools showed that Filipino adolescents consumed substantially fewer servings of vegetables than the recommended daily allowances.[27]

\section{Snacking}

Gunes, et al. defined a snack to mean foods and drinks taken outside the components of the three major meals. [28] The current study showed that frequent snacking is a risk factor for becoming overweight and obese across genders. In the Philippines, a study undertaken at The lligan National High School showed that students aged 14-15 years old chose soft drinks, biscuits, cakes, sandwiches and puto (rice cake) during snack time.[29] Snacking may 
be a contributory factor to gaining positive energy levels and eventually an increase in body weight. Poor snacking such as consuming ice cream, cupcakes, chips and cookies should be discouraged because these foods are basically high in calories and low in nutrients.[30] In this present study, the authors hypothesized that the results may attribute to the availability and accessibility of energy dense foods, sugary foods and beverages and fast foods inside the university.

Contrary to the present study, Gunes, et al. showed that frequent consumption of snacks appeared to be protective of becoming overweight/ obese among university students in the universities in Istanbul, Turkey.[28] Suarez, et al. (2015) also reported that snacking frequency is not related to the odds of being overweight but emphasized that the number of servings from snacking was significantly associated to being overweight.[15]

\section{Limitation}

This research is without any limitations. While the initial target sample size was not met, in the two-tailed post hoc exact test for multiple regression (random model) using $G$ *Power 3.1 1.9.2 it was found that the included sample of $n=1401$ had a power of 1.00. $[31,32]$ Although the observed significant prevalence of being overweight and obesity may reflect situations among individuals in the same age and school-based population, this investigation was a cross-sectional study limited to one university alone. A multi-center study may reveal data that can be reflective of the national prevalence. In addition, a longitudinal study would show a better relationship of eating and lifestyle habits with obesity among university students. Relative to the questionnaire used, details such as the nutritional component and type of food can be further explored to clearly show the association of the dietary habits and BMI. Also, in terms of snacking, factors such as timing, calories and type of snack foods eaten should be further explored.

\section{CONCLUSION}

This study concluded that there is a large percentage of student population who are particularly overweight and obese, specifically males. Eating breakfast and vegetables are protective in being overweight and obese, while taking frequent snacks is a risk factor in being overweight and obese for both genders. Obesity can occur at any age. Clearly, college students would profit from health promotion programs that focus on these important health concerns. Health education classes, wellness programs and healthy food choices in university cafeteria are some of the possible health promotion interventions that should benefit the university community. College and university web and journals can be used to carry health education messages. More investigations associating obesity with eating habits and lifestyle practices can be done in the future. 


\section{REFERENCES}

1. Ramachandran A, Snehalatha C. Rising burden of obesity in Asia. Journal of Obesity. 2010 Aug 30;2010:868573.

2. Gumaro M. 8th National Nutrition Survey. FNRI Website. $\quad$ http://www.fnri.dost.gov.ph/index.php/ nutrition-statistic/19-nutrition-statistic/118-8th-national-nutrition-survey. Accessed May 10, 2018.

3. Bushman B. American College of Sports Medicine. ACSM's Complete Guide to Fitness \& Health, 2E. Human Kinetics; 2017 Jan 23.

4. Gonzalez-Suarez CB, Grimmer-Somers K. The association of physical activity and physical fitness with pre-adolescent obesity: an observational study in Metromanila, Philippines. Journal of Physical Activity and Health. 2011 Aug;8(6):804-10.

5. Sun $Y$, Sekine $M$, Kagamimori S. Lifestyle and overweight among Japanese adolescents: The Toyama Birth Cohort Study. Journal of Epidemiology. 2009;19(6):303-10. doi:10.2188/jea.je20080095.

6. Azadbakht L, Hajishafiee M, Golshahi J, Esmaillzadeh A. Snacking behavior and obesity among female adolescents in Isfahan, Iran. Journal of the American College of Nutrition. 2016 Jul 3;35(5):405-12.

7. Magbuhat T, Borazon EQ, Villarino JB. Food preferences and dietary intakes of Filipino adolescents in metro Manila, the Philippines. Malaysian Journal of Nutrition. 2011 Mar $1 ; 17(1): 31-41$.

8. Tzischinsky $O$. The association between sleeping patterns, eating habits, obesity, and quality of life among Israeli adolescents. Cogent Psychology. 2016 Dec 31;3(1):1223903.

9. Racette SB, Deusinger SS, Strube MJ, Highstein GR, Deusinger RH. Weight changes, exercise, and dietary patterns during freshman and sophomore years of college. Journal of American College Health. 2005 May 1;53(6):245-51.

10. Lee J, Johnson C, Rice J, Warren CW, Chen T. Smoking beliefs and behavior among youth in South Korea, Taiwan, and Thailand. International Journal of Behavioral Medicine. 2013 Sep 1;20(3):319-26.

11. Seo DC, Huang Y. Systematic review of social network analysis in adolescent cigarette smoking behavior. Journal of School Health. 2012 Jan;82(1):21-7.

12. Hingorjo MR, Syed S, Qureshi MA. Overweight and obesity in students of a dental college of Karachi: lifestyle influence and measurement by an appropriate anthropometric index. JPMA. The Journal of the Pakistan Medical Association. 2009 Aug;59(8):528.

13. Barr SI, DiFrancesco L, Fulgoni VL. Association of breakfast consumption with body mass index and prevalence of overweight/obesity in a nationally-representative survey of Canadian adults. Nutrition Journal. 2015 Dec;15(1):33.

14. Kutty NA, Ru TY, Chiang VH, Zhi WY. Association of dietary habits and body mass index among university students in Malaysia: a cross-sectional study. J Nurs Health Sci. 2015;4(5):78-85.

15. Gonzalez-Suarez CB, Lee-Pineda K, Zamora MT, Sibug EO, Velasco ZF, Grimmer-Somers K. Cardiovascular fitness and caloric intake in Filipino obese children: an observational study. Asian Journal of Clinical Nutrition. 2012 Jul $1 ; 4(3): 88-97$.
16. Gonzalez-Suarez CB, Lee-Pineda K, Caralipio ND, GrimmerSomers K, Sibug EO, Velasco ZF. Is what Filipino children eat between meals associated with body mass index? Asia Pacific Journal of Public Health. 2015 Mar;27(2):NP650-61.

17. Cole TJ, Bellizzi MC, Flegal KM, Dietz WH. Establishing a standard definition for child overweight and obesity worldwide: international survey. BM. 2000 May 6;320(7244):1240.

18. Sakamaki R, Amamoto R, Mochida Y, Shinfuku N, Toyama K. A comparative study of food habits and body shape perception of university students in Japan and Korea. Nutrition Journal. 2005 Dec;4(1):31.

19. Yahia N, Achkar A, Abdallah A, Rizk S. Eating habits and obesity among Lebanese university students. Nutrition Journal. 2008 Dec;7(1):32.

20. Al-Rethaiaa AS, Fahmy AE, Al-Shwaiyat NM. Obesity and eating habits among college students in Saudi Arabia: a cross sectional study. Nutrition Journal. 2010 Dec;9(1):39.

21. 36-Item Short Form Survey from the RAND Medical Outcomes Study. RAND Corporation. Available at: https://www. rand.org/health/surveys_tools/mos/36-item-short-form. html. Accessed March 31, 2018.

22. Pengpid S, Peltzer K. Prevalence of overweight and underweight and its associated factors among male and female university students in Thailand. HOMO-Journal of Comparative Human Biology. 2015 Apr 1;66(2):176-86.

23. Thompson-McCormick JJ, Thomas JJ, Bainivualiku A, Khan AN, Becker AE. Breakfast skipping as a risk correlate of overweight and obesity in school-going ethnic Fijian adolescent girls. Asia Pacific Journal of Clinical Nutrition. 2010;19(3):372.

24. Saikia D, Ahmed SJ, Saikia H, Sarma R. Overweight and obesity in early adolescents and its relation to dietary habit and physical activity: A study in Dibrugarh town. Clinical Epidemiology and Global Health. 2016 Jan 1;4:S22-8.

25. Gazibara T, Teparcevic DB, Popovic A, Pekmezovic T. Eating habits and body-weights of students of the University of Belgrade, Serbia: a cross-sectional study. Journal of Health, Population, and Nutrition. 2013 Sep;31(3):330.

26. Al-Hazzaa HM, Abahussain NA, Al-Sobayel HI, Qahwaji DM, Musaiger AO. Lifestyle factors associated with overweight and obesity among Saudi adolescents. BMC Public Health. 2012 Dec;12(1):354.

27. Gonzales JT, Raaii JV, Narciso ZV. Consumption pattern for fruits and vegetables of some Filipino adolescents in selected public schools in the city of Manila. J Nutr Disorders Ther. 2016;6(4):1-7.

28. Gunes FE, Bekiroglu N, Imeryuz N, Agirbasli M. Relation between eating habits and a high body mass index among freshman students: a cross-sectional study. Journal of the American College of Nutrition. 2012 Jun 1;31(3):167-74.

29. Waweru WR, Marete OT. Estimation of relationship between eating habits and body mass index of students in Mount Kenya University, Rwanda.

30. Febro RD, Ramayan AJ, Sepe AR, Burgos JV, Lorion AP, Macaraeg ML. Snack Choices and Nutritional Awareness of Students in lligan City National High School.

31. Faul F, Erdfelder E, George-Lang A, Buchner A. G*Power 3: A flexible statistical power analysis program for the social, behavioral, and biomedical sciences. Behavior Research Methods. 2007;39(2):175-91. 
32. Faul F, Erdfelder E, George-Lang A, Buchner A. Statistical power analyses using G*Power 3.1: Tests for correlation and regression analyses. Behavior Research Methods. 2009;41(4): $1149-1160$ doi:10.3758/BRM.41.4.1149.

(c) (i) Open Access This article is licensed under a Creative Commons Attribution 4.0 International License, which permits use, sharing, adaptation, distribution and reproduction in any medium or format, as long as you give appropriate credit to the original author(s) and the source, provide a link to the Creative Commons license, and indicate if changes were made. The images or other third party material in this article are included in the article's Creative Commons license, unless indicated otherwise in a credit line to the material. If material is not included in the article's Creative Commons license and your intended use is not permitted by statutory regulation or exceeds the permitted use, you will need to obtain permission directly from the copyright holder. To view a copy of this license, visit http://creativecommons.org/licenses/by/4.0/. 